\title{
Um estudo sobre o grau de importância atribuído pelo investidor à utilização de modelos matemáticos na prática de home broker
}

\begin{abstract}
RESUMO
Este trabalho propõe o exame do grau de importância atribuído pelo pequeno investidor praticante da modalidade home broker quanto ao uso de modelos matemáticos no processo de escolha de seus investimentos. A pesquisa caracteriza-se como um estudo exploratório, com levantamento bibliográfico e de campo, coleta de dados realizada por meio da aplicação de questionários e análise estatística descritiva e inferencial. Fundamentado nos resultados da apreciação da amostra, o estudo tece considerações sobre a incidência da utilização de gráficos e relatórios oriundos de modelos matemáticos, quanto aos critérios de escolha da corretora em relação às ferramentas de simulação oferecidas e à funcionalidade do portal eletrônico. Complementarmente, identifica a importância dada pelos respondentes aos fatores política internacional e política interna brasileira, bem como à cotação da moeda internacional.
\end{abstract}

Palavras-chave: Decisões em investimento. Home broker. Modelos matemáticos.

André Andrade Longaray longaray@yahoo.com.br Professor Associado lotado no Instituto de Ciências Econômicas, Administrativas e Contábeis - ICEAC/FURG 


\section{INTRODUÇÃO}

O mercado de investimentos torna-se cada vez mais popular entre os brasileiros, mas, mesmo com esse crescimento, muitas pessoas ainda não sabem como começar a investir, principalmente pelo fato de desconhecerem os meios utilizados para se operar no mercado de capitais.

Existem várias formas disponíveis de se operar o sistema de compra e venda de ações, uma delas é via internet. O home broker é uma ferramenta oferecida pela Bolsa de Valores, Mercadorias e Futuros de São Paulo (Bovespa), que permite a negociação de ações pela web. É uma forma de negociação de papéis na bolsa de valores por intermédio de ordens emitidas em meio eletrônico para corretoras de títulos mobiliários regularmente credenciadas.

A ferramenta home broker torna mais ágil e simples as negociações no mercado acionário, o que explica a forte expansão no número de usuários nos últimos anos. Entretanto, ao mesmo tempo em que a ferramenta cria um facilitador de entrada de investidores, há alguns riscos inerentes ao mercado de ações, riscos operacionais do uso da internet e riscos relacionados ao ciclo de liquidação, que devem ser observados.

Atualmente, existem mais de sessenta corretoras habilitadas a negociar ações na Bolsa de Valores. Com essa variedade nas formas de sistema e corretoras, surge a indecisão do investidor em analisar e tomar a decisão de qual a melhor alternativa para o tipo de negociação que ele possui o objetivo de realizar.

Uma forma de avaliar cartas de investimento se dá pela aplicação de modelos matemáticos. Esses modelos têm como objetivo determinar os parâmetros da decisão, a viabilidade ou o percentual de sucesso de uma determinada alternativa, assim como estabelecer os efeitos e consequências de sua implementação.

Nesse contexto, o objetivo do presente texto é analisar a importância atribuída pelo pequeno investidor usuário da modalidade home broker à utilização de modelos matemáticos no processo de escolha de seus investimentos. Subsidiariamente, pretende-se identificar os fatores que influenciam o investidor na escolha de uma corretora para realizar suas operações home broker e os aspectos macroeconômicos que implicam sua decisão de investimento.

Em uma perspectiva metodológica, esta pesquisa caracteriza-se, quanto aos seus fins, como um estudo exploratório. No que diz respeito aos meios, pode ser descrita como uma pesquisa bibliográfica e de campo. O processo de coleta de dados se deu por meio de aplicação de questionários aplicados à uma amostra composta de 55 pequenos investidores no mercado de ações, escolhidos de forma intencional, e levantamento de documentos. A análise dos dados teve caráter predominantemente quantitativo.

Este artigo está dividido em cinco seções. Estabelecido o marco introdutório, a seção 2 apresenta a revisão bibliográfica que fundamenta a pesquisa. Na seção 3, são descritos os procedimentos metodológicos. A seção 4 expõe os dados, a análise e os resultados da pesquisa. Por fim, a seção 5 traz as considerações finais a respeito do trabalho.

\section{REFERENCIAL TEÓRICO}

Esta seção discorre acerca dos fundamentos teóricos que embasam a pesquisa. Nesse sentido, abordam-se aspectos conceituais sobre o mercado de capitais, o sistema home broker e os modelos matemáticos aplicados à área de investimentos em ações.

\subsection{Mercado de capitais}

O mercado de capitais é um sistema de distribuição de valores mobiliários que proporciona liquidez aos títulos de emissão de empresas e viabiliza o processo de capitalização. Pinheiro (2009, p. 174) define o mercado de capitais como

sendo um conjunto de instituições que negociam com títulos e valores mobiliários, objetivando a canalização dos recursos dos agentes compradores para os agentes vendedores. Ou seja, o mercado de capitais representa um sistema de distribuição de valores mobiliários que tem o propósito de viabilizar a capitalização das empresas e dar liquidez aos títulos emitidos por elas.

Esse mercado existe com o objetivo de garantir um fluxo de recursos nas condições adequadas em termos de prazos, custos e exigibilidades, pois o mercado de crédito deixou de atender a essas 
necessidades da atividade produtiva. Assaf Neto (2003, p. 124), em seus estudos, admite que

\begin{abstract}
o mercado de Capitais assume papel dos mais relevantes no processo de desenvolvimento econômico. É o grande municiador de recursos permanentes para a economia, em virtude da ligação que efetua entre os que têm capacidade de poupança, ou seja, os investidores, e aqueles carentes de recursos de longo prazo, ou seja, que apresentam déficit de investimento.
\end{abstract}

No mercado de capitais, os principais títulos negociados são os representativos do capital de empresas (as ações), ou os oriundos de empréstimos tomados, via mercado, por empresas (debêntures conversíveis em ações, bônus de subscrição e comercial papers), que permitem a circulação para custear o desenvolvimento econômico. Igualmente, abrange as negociações com direitos e recibos de subscrição de valores mobiliários, certificados de depósitos de ações e demais derivativos autorizados à negociação.

O mercado de ações pode ser dividido em duas etapas: o mercado primário, quando as ações de uma empresa são emitidas diretamente ou por uma oferta pública, e o mercado secundário, no qual as ações já emitidas são comercializadas por intermédio da bolsa de valores.

Fortuna (2005, p. 559) conceitua, em síntese, a bolsa de valores como "o local especialmente criado e mantido para negociação de valores mobiliários em mercado livre e aberto, organizado pelas corretoras e autoridades".

\title{
2.2 Home broker
}

Inserido no contexto do mercado secundário de ações está o sistema home broker. Essa modalidade começou a ser implementada no Brasil a partir de 1999 em decorrência dos avanços tecnológicos na área da informática.

Em sua essência, o home broker é um sistema oferecido pela Bolsa de Valores, Mercadorias e Futuros de São Paulo (BM\&FBovespa), utilizado para conectar usuários ao pregão eletrônico no mercado de capitais. Usado como instrumento para negociação no mercado de capitais via internet, permite que sejam enviadas ordens de compra e venda pelo site de uma corretora na internet (ANDERSEN, 2006).

Fortuna (2005, p. 564) conceitua home broker como

\begin{abstract}
um canal de relacionamento entre investidores, corretoras e o sistema de pregão eletrônico da Bovespa. Nesse sistema, qualquer pessoa pode acompanhar a cotação do papel e fazer a oferta de compra ou venda, fechando, assim, o negócio sem a necessidade de um operador, o investidor é o próprio operador. Todas as ações listadas na Bovespa são negociadas pelo sistema eletrônico e a tendência é de que no mercado só fique essa modalidade de pregão.
\end{abstract}

Complementa Fortuna (2005, p. 564), ainda, afirmando a quem se destina esse sistema eletrônico:

\begin{abstract}
A negociação no mercado fracionário tem como alvo os pequenos investidores, pois se negociam quantidades menores do que o à vista, só pode ser feita via sistema eletrônico. Essa negociação é mais cômoda para o pequeno investidor, pois não há como cair em casos de leilão. A interferência do viva voz, nesse caso, é nenhuma.
\end{abstract}

As negociações são realizadas durante o pregão da Bovespa, criado com o intuito de aumentar a quantidade de investidores e baratear o processo de compra e venda de ações, que tem seu funcionamento regular de segunda a sexta-feira das 10 às 17 horas.

Além do horário regular de pregão, também existe o After Market, pelo qual é possível realizarem-se operações com alguns parâmetros de restrição regulados pela Bovespa quanto às ações negociadas, à oscilação de preços e quantidades negociadas de uma única ação por um único cliente. O funcionamento se dá de segunda a sexta-feira das $17 \mathrm{~h}$ e $45 \mathrm{~min}$ às $18 \mathrm{~h}$ e $30 \mathrm{~min}$.

Fora dos horários de negociação, pela internet, via sistema operacional home broker, o cliente poderá enviar suas ordens a qualquer horário do dia ou da noite. Entretanto, apesar de a corretora acatar suas ordens, a efetiva participação do cliente nas negociações somente se dará a partir do pregão/horário de negociação imediatamente mais próximo.

\subsection{Modelos matemáticos}

Os modelos matemáticos são cada vez mais utilizados no mundo real, com o objetivo de 
diminuir incertezas no processo decisório (LONGARAY, 2013). No universo das ações, esses modelos também vêm tornando-se essenciais para um investidor, em razão das grandes mudanças sofridas pelo mercado de capitais a cada instante.

A utilização de modelos matemáticos justifica-se, uma vez que implica uma análise detalhada dos componentes do problema, alinhando-os em uma estrutura lógica para que, então, seja aplicada uma metodologia adequada ao tipo de problema; assim sendo, o resultado encontrado será avaliado em uma tomada de decisão (MOTTA JUNIOR; OLIVEIRA; GUTIERREZ, 2007).

Inserido nesse contexto, o maior desafio dos Mercados Financeiros e de Capitais é o de combinar a máxima rentabilidade com um baixo risco.

Corrêa e Souza (2001) descrevem um conceito estruturado por Harry Markowitz (1952), em que ele enuncia, em seu artigo, as bases sobre as quais se afirmou a Moderna Teoria de Investimentos. De acordo com a teoria de Markowitz, os investidores podem determinar todas as carteiras "ótimas", no sentido risco e retorno, e formar a fronteira eficiente. A fronteira eficiente pode ser descrita como o melhor conjunto possível de carteiras, isto é, todas as carteiras têm o mínimo nível de risco para dado nível de retorno. Os investidores se concentrariam na seleção de uma melhor carteira na fronteira eficiente e ignorariam as demais, consideradas inferiores.

Vasarhelyi $(1976$, p. 7) afirma que

\begin{abstract}
o modelo tradicional de análise e otimização de carteiras de investimento foi proposto por Markowitz. Este modelo tenta maximizar o retorno proveniente de uma carteira de investimentos, minimizando o seu risco. As medições de risco são feitas através da variância no retorno histórico das ações da carteira. A minimização de risco é feita através de um balanceamento entre ações que seguem o ciclo econômico e ações que são contra cíclicas. As relações entre as ações são calculadas pela covariância entre os preços das ações. Por outro lado, este modelo torna-se de difícil utilização, pois envolve o cálculo extensivo de covariâncias, o que, com o acréscimo do número de ações, representa uma tarefa quase impossível. Outra dificuldade pouco contornável é a preparação de dados para este modelo, o que requer a incorporação de dividendos e bonificações ao preço de cada ação antes de se poder calcular o seu retorno real.
\end{abstract}

De acordo com Colin (2007), o investidor tem como objetivo o retorno máximo com um risco mínimo em suas aplicações; esses interesses, porém, seriam conflitantes, uma vez que a noção de que um risco maior leva a um maior retorno é quase intuitiva e se não fosse assim não faria sentido. Desse modo, o investimento poderia ser analisado de duas maneiras. A primeira diz respeito a maximizar o retorno, considerando um nível máximo de risco a ser assumido; a segunda, minimizar o risco, levando em conta uma rentabilidade mínima a ser obtida.

Motta Junior, Oliveira e Gutierrez (2007) afirmam que, na seleção de ações para investimento, a modelagem matemática permite escolher a melhor das combinações de ativos sob a ótica da Teoria das Carteiras de Markowitz, ou seja, o risco de uma carteira depende do risco de cada elemento que a compõe, de sua participação no investimento total e da forma com que seus componentes relacionam-se entre si.

O modelo de Markowitz (1952) pode ser genericamente definido por:

$$
\begin{aligned}
& \text { Min z }=\sum_{i, j=1}^{n} \operatorname{cov}\left(r_{i}, r_{j}\right) w_{i} w_{j} \\
& \text { Sujeito a: } \sum_{j=1}^{n} r_{j} w_{j} \geq r \\
& \qquad \sum_{j=1}^{n} w_{j}=1 \\
& w_{j} \geq 0 \text { para } j=1,2, \ldots, n
\end{aligned}
$$

Colin (2007, p. 340) destaca que a maior dificuldade do uso desse modelo é "a definição das rentabilidades esperadas por tipo de investimento". O autor ressalta que não é recomendável simplesmente usar dados históricos para estimar o retorno de um mercado, ou de algum ativo em particular. Isso se deve à grande diferença entre valores tipicamente observados de rentabilidade $\mathrm{e}$ variância da rentabilidade.

A conclusão a que Corrêa e Souza $(2001$, p. 9) chegam é que, 


\begin{abstract}
Diversificar não significa simplesmente "colocar ovos em cestas diferentes", mas um processo de avaliação de alocação de capital em diversas oportunidades de ganho (ou perda), por meio da determinação de duas contribuições para a otimização da relação risco-retorno.
\end{abstract}

Os pequenos investidores vêm utilizando modelos e ferramentas para realizar seus investimentos. A variedade destes pode tornar difícil a escolha do mais adequado, visto que possuem características específicas e, por serem complexos, não serem compreendidos pelos investidores. Mesmo com um aumento do uso dessas ferramentas e modelos, com um maior entendimento dos pequenos investidores, ainda há de se explorar o tema.

Para isso, algumas pesquisas recentes apresentam a relação de modelos matemáticos, ferramentas de investimento e pequenos investidores. Sendo, para tal, considerada a existência de várias outras possibilidades matemáticas para a escolha de uma carteira de investimento, tais como a otimização combinatória, as programações linear e não linear, a análise envoltória de dados (DEA), entre outras (ANDERSEN, 2006; PINHEIRO, 2009).

Kawamoto (2010) esclarece que o home broker penetrou no mercado de Capitais brasileiro por meio de modelos lineares, modelo de Fisher-Pry e do modelo de Gompertz. Já Testa (2011) utilizouse da estratégia de investimento de Graham associada à BMF\&Bovespa para o pequeno investidor.

Como auxílio para o pequeno investidor, Bratti (2009) elaborou um sistema informatizado que se torna mais uma opção, ao lado do home broker e do Folhainvest, para esse tipo de investidores.

Utilizando-se de outros modelos matemáticos, Gonçalves Jr., Pamplona e Montevechi (2002) apresentam a teoria de Markowitz como base para seleção de carteiras de pequenos investidores. Já, Lopes et al. (2009) promovem, como estratégia para seleção de carteiras de investimento, o uso da Análise Envoltória de Dados (DEA).

\title{
3 PROCEDIMENTOS METODOLÓGICOS
}

O presente estudo, quanto aos fins, pode ser descrito como uma pesquisa de caráter exploratório, na qual se pretende proporcionar um maior entendimento sobre como os investidores que empregam seus recursos na modalidade home broker fazem uso de modelos matemáticos para diminuir o risco ao tomar suas decisões no mercado de investimentos (ROESCH, 2005).

Quanto aos meios, a pesquisa é bibliográfica e de campo. Bibliográfica, porque, para a fundamentação teórico-metodológica do trabalho, foi realizado um procedimento investigatório a respeito dos assuntos relacionados ao mercado de investimento e da ferramenta home broker, bem como sobre os modelos matemáticos possíveis de serem aplicados a essa ferramenta. A investigação coletou dados empíricos em sites de corretoras de ações, utilizados para manusear a ferramenta home broker. Incluindo, ainda, a aplicação de questionários com investidores do mercado de ações.

A pesquisa tem caráter quantitativo, pois foram analisados dados mensuráveis e utilizadas técnicas estatísticas para medir esses dados.

A população deste estudo foram os investidores que utilizam a ferramenta de compra e venda de ações por meio do sistema home broker. A amostra foi constituída de 55 investidores predeterminados de forma não probabilística, selecionados por acessibilidade e tipicidade. Isso quer dizer que tais investidores foram selecionados independentemente de procedimento estatístico, mas por critérios de acessibilidade e elementos considerados representativos na concepção da pesquisa.

Foi utilizada como técnica de coleta de dados, preliminarmente, a pesquisa bibliográfica, na qual se verificou o material já existente acerca dos aspectos principais do estudo, bem como se viabilizaram comparações entre diversas opiniões de autores distintos.

Para coleta dos dados primários, foi utilizada a técnica de questionário. O questionário utilizado para coletar os dados foi construído tendo como aporte aspectos vislumbrados durante o processo de revisão bibliográfica e é constituído de dezesseis questões, sendo doze delas configuradas como do tipo fechadas e as outras quatro questões do tipo misto (fechadas/abertas).

\section{ANÁLISE DOS DADOS E RESULTADOS}

Nesta seção, são descritos os passos da análise dos dados coletados e dos resultados da pesquisa. Inicialmente, apresenta-se a estrutura do questionário aplicado na amostra. Na sequência, expõe-se 
a estatística das questões. Por fim, discorre-se sobre os resultados do trabalho.

\subsection{Estrutura do questionário}

O questionário elaborado foi estruturado de forma a obter dos respondentes informações que permitissem aos pesquisadores delinearem um perfil da amostra quanto aos objetivos da pesquisa.

Nesse sentido, as questões 5 (disponibilidade de gráficos), 6 (importância de relatórios), 10 (tipo de instrumento analítico) e 11 (princípio da diversificação) objetivam investigar acerca do comportamento do investidor que utiliza a ferramenta home broker quanto aos modelos matemáticos.

Outro fator que o questionário buscou investigar foi a identificação de quais as variáveis que mais influenciam no momento da tomada de decisão do investidor, no que tange à utilização de relatórios de análise de mercado, cotação do dólar, índice Bovespa, política brasileira e política internacional (questões 12, 13 e 14).

Por fim, o questionário aborda questões referentes à tomada de decisão no momento de o investidor escolher a corretora na qual se cadastra. As questões 3 (fator relevante na hora da escolha da corretora), 4 (importância do monitoramento de papéis, 5 (disponibilidade de gráficos), 6 (disponibilidade de relatórios), 7 (importância de assessor), 8 (sugestões de estratégias), 9 (preço de corretagem) e 16 (influência da Tecnologia da Informação) englobam essa preocupação.

\subsection{Análise dos dados}

Inicialmente, foi identificado o perfil da amostra. Foram respondidos 55 questionários. Por meio dos dados obtidos, foi possível observar que $96 \%$ dos entrevistados possuem idade inferior a 36 anos, consequentemente, apenas $2 \%$ possuem idade entre 36 e 55, bem como $2 \%$ estão na faixa entre 56 e 65 anos. Nenhum entrevistado tinha idade superior a 65 anos. 0 desvio padrão está conceituado como a medida mais comum da dispersão estatística, ou seja, é a média das diferenças entre o valor de cada evento e a média central. No caso das idades das pessoas entrevistadas, esse valor é de 26,17091.

Ainda sobre o perfil da amostra, procurou-se estabelecer a finalidade dos investimentos dos entrevistados. A opção com maior frequência foi a referente ao "crescimento substancial do patrimônio", que atingiu o índice de $75 \%$. A alternativa "consumo" obteve um percentual de $22 \%$, seguida pela opção "aposentadoria", com $2 \%$ dos investidores pesquisados. A opção relacionada à "proteção do capital contra a inflação" não foi considerada por nenhum entrevistado. No quesito desvio padrão, essa questão obteve um índice de 15,6333.

$\mathrm{Na}$ análise do comportamento dos investidores quanto ao uso de modelos matemáticos, foram realizadas questões para identificar a importância da utilização de gráficos no exame das carteiras de investimento e o conhecimento por parte do entrevistado a propósito de qual ferramenta matemática sua corretora home broker utiliza e quanto ao conhecimento do princípio da diversificação.

No que se refere ao uso de instrumentos gráficos, $64 \%$ dos investidores pesquisados acreditam ser de muita importância a disponibilidade de gráficos; já $31 \%$ creem que os gráficos são apenas importantes. Por outro lado, 5\% consideram referido quesito de pouca importância, mas nenhum dos entrevistados acredita que não tenham nenhuma importância. Com isso, é possível observar que a maioria dos investidores utiliza ferramentas estatísticas, como gráficos, para auxiliarem na sua tomada de decisão, conforme ilustra o Gráfico 1.

Gráfico 1 - Importância da disponibilidade de gráficos na decisão sobre investimento home broker

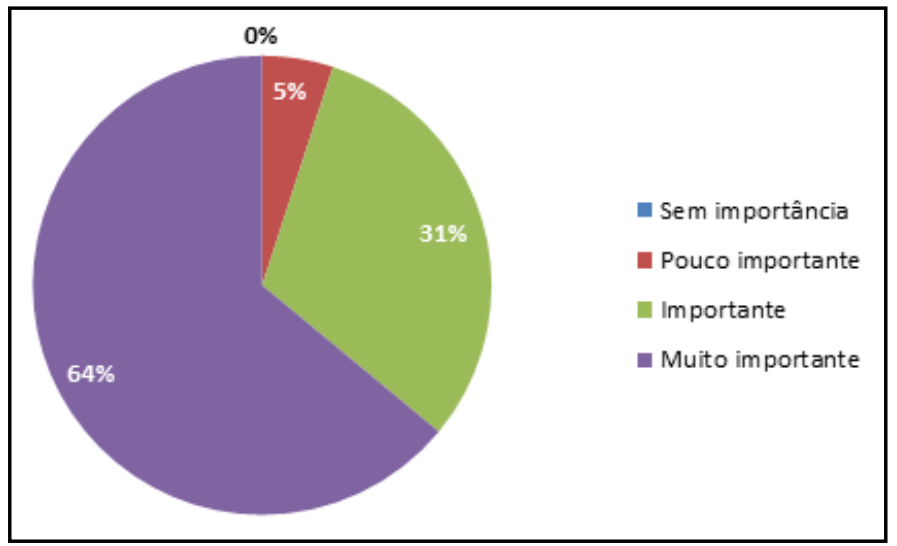

Fonte: Dados da pesquisa (2014) 
No levantamento amostral sobre qual tipo de instrumento analítico é utilizado pela corretora para operar a ferramenta home broker, foi possível observar que $55 \%$ dos entrevistados identificam o uso do Portfólio Selection, em que a corretora determina todas as carteiras "ótimas", avaliando o risco e o retorno de cada uma delas, trabalhando, dessa maneira, com a diversificação de investimentos. Já $18 \%$ dos entrevistados utilizam o modelo de Programação Linear, no qual a corretora designa um montante fixo de recurso que satisfaça tanto as condições mínimas de recursos quanto as condições mínimas do mercado a fim de otimizar o lucro total de investimentos, em uma projeção linear dos lucros. Por outro lado, $13 \%$ utilizam um modelo semelhante, mas, em uma projeção não linear dos lucros, este é denominado Programação Não Linear. Além disso, 15\% desconhecem o modelo utilizado pela sua corretora, o que pode ser considerado um índice elevado, tratando-se da aplicação de recursos financeiros. O Gráfico 2 ilustra essa distribuição.

Gráfico 2 - Modelos matemáticos usados pelas corretoras em investimentos home broker

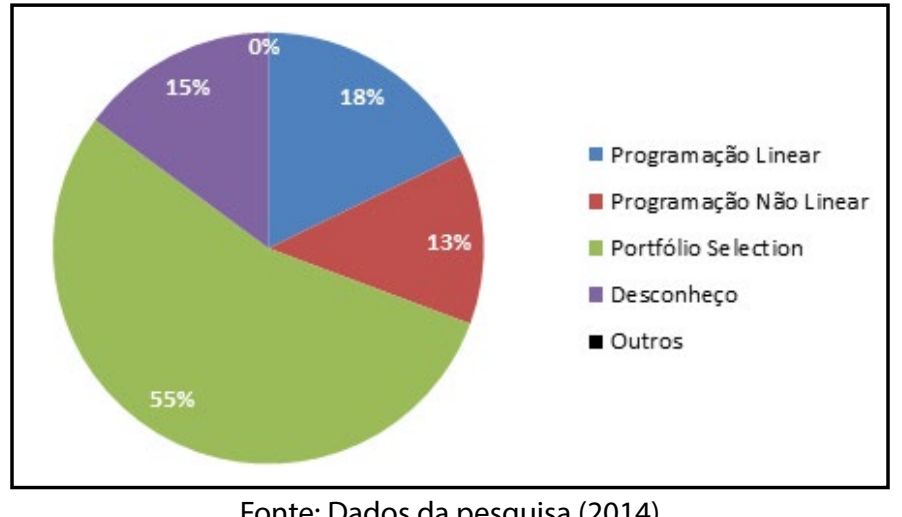

Quanto ao conhecimento e uso do Princípio da Diversificação, 47\% dos entrevistados consideraram importante a sua utilização, seguido por $38 \%$ que julgam ser muito importante o uso de tal Princípio. Por outro lado, 13\% acreditam ser de pouca importância e 2\% pensam ser totalmente sem importância a utilização do mencionado quesito. É possível concluir que, mesmo sendo a maioria da amostra operadora do modelo de Portfólio Selection, alguns entrevistados não julgam ser de tamanha importância o Princípio da Diversidade. Dos que utilizam o Portfólio Selection, que são $55 \%$ dos entrevistados, 53,3\% acreditam que o Princípio é muito importante, 43,3\% pensam que é importante e 3,3\% julgam ser de pouca importância. Uma resposta possível seria a de que não adianta diversificar sem nenhum critério, é necessário um processo de avaliação de alocação de capital em diversas oportunidades de ganho (ou perda), por meio da determinação de duas contribuições para a otimização da relação risco-retorno (Gráfico 3).

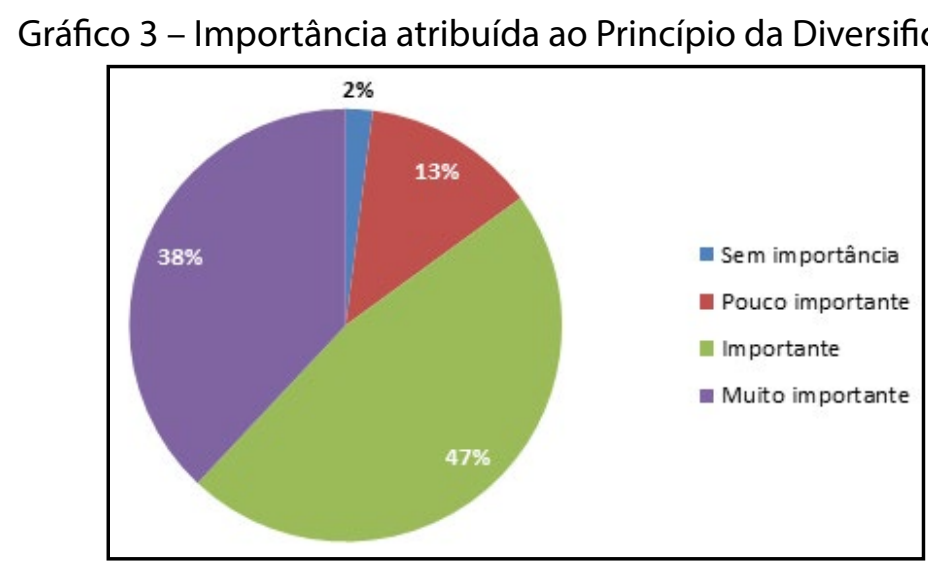

Fonte: Dados da pesquisa (2014)

Em outra perspectiva, o questionário da pesquisa procurou identificar na amostra as variáveis que mais influenciam no momento da tomada de decisão do investidor, com as questões referentes a relatórios de análise de mercado, cotação do dólar, índice Bovespa, política brasileira e política internacional. 
Foi possível perceber que 53\% pensam ser muito influente o índice Bovespa, uma parcela da amostra um pouco maior da que acredita ter o dólar grande influência no Mercado de Ações. Já 38\% julgam ser apenas influente citado índice para com as ações que o operador investe. De outro modo, $7 \%$ acreditam ter pouca influência, bem como $2 \%$ julgam ser sem nenhuma influência.

No que se refere à influência da política brasileira no Mercado de Ações, $47 \%$ dos entrevistados julgam ser de muita influência, acreditando ser esse fator fundamental para aumento ou declínio do valor de suas ações. Já $40 \%$ possuem o pensamento de que a política brasileira é apenas importante, não afetando tanto no valor de suas ações em comparação a outros fatores. Contrariamente a essas ideias, $11 \%$ escolheram a opção que indica ser a política brasileira pouco influente relativamente às suas ações, e $2 \%$ acreditam ser de nenhuma influência.

Após analisar a influência da política brasileira na decisão sobre investimento, observou-se a influência do mercado internacional no que diz respeito ao Mercado de Ações brasileiro. No quesito em foco, uma maioria bem considerável dos entrevistados julga ser de muita influência o mercado internacional em relação ao Mercado de Ações brasileiro, 73\% dos entrevistados compartilham dessa ideia. Já $20 \%$ dos investidores entrevistados pensam ser apenas influente. Como nos fatores anteriores, existem os investidores que divergem da opinião da maioria; no caso, $5 \%$ pensam ser de pouca influência, assim como $2 \%$ julgam ser sem nenhuma influência. O Gráfico 4 ilustra o quanto o mercado internacional influencia as decisões de investimento sobre a perspectiva da amostra investigada.

Gráfico 4 - Influência da política internacional na decisão sobre investimento home broker

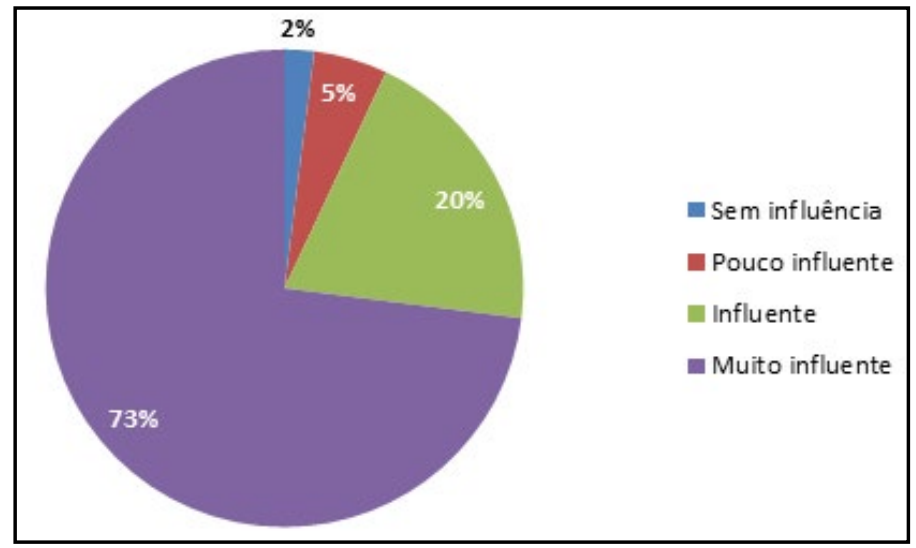

Fonte: Dados da pesquisa (2014)

A terceira parte do questionário envolveu questões que procuraram identificar na amostra quais os aspectos que influenciam o entrevistado na escolha da corretora de ações. Foram analisados fatores como preço de corretagem, segurança e tecnologia da informação e assessoria prestada.

Dos referidos fatores, o quesito segurança das transações foi o que obteve o maior percentual de influência $-60 \%$ dos entrevistados. Foi possível observar que, nos dias de hoje, o principal fator que preocupa o investidor é o de segurança. A imagem e credibilidade do portal foi a segunda com maior índice de respostas, obtendo um percentual de 16\%, provavelmente ainda referente à segurança das transações, pois quanto maior a credibilidade do portal, pode-se presumir uma maior segurança nas transações dos investidores.

Já $15 \%$ dos entrevistados julgam serem as ferramentas disponibilizadas pelo portal como fator de maior importância na hora de escolher sua corretora. E, por último, está a alternativa relativa ao preço da corretagem, que obteve um percentual de $9 \%$ dos entrevistados. Desse modo, é possível observar que o investidor não considera de muita relevância o preço da corretagem no momento de escolher seu home broker.

O Gráfico 5 demonstra a relação percentual entre os fatores que impactam na decisão do investidor da amostra pesquisada quanto à escolha da corretora de ações para a realização das operações de home broker. 


\section{Gráfico 5 - Fatores que influenciam os investidores na escolha da corretora de ações}

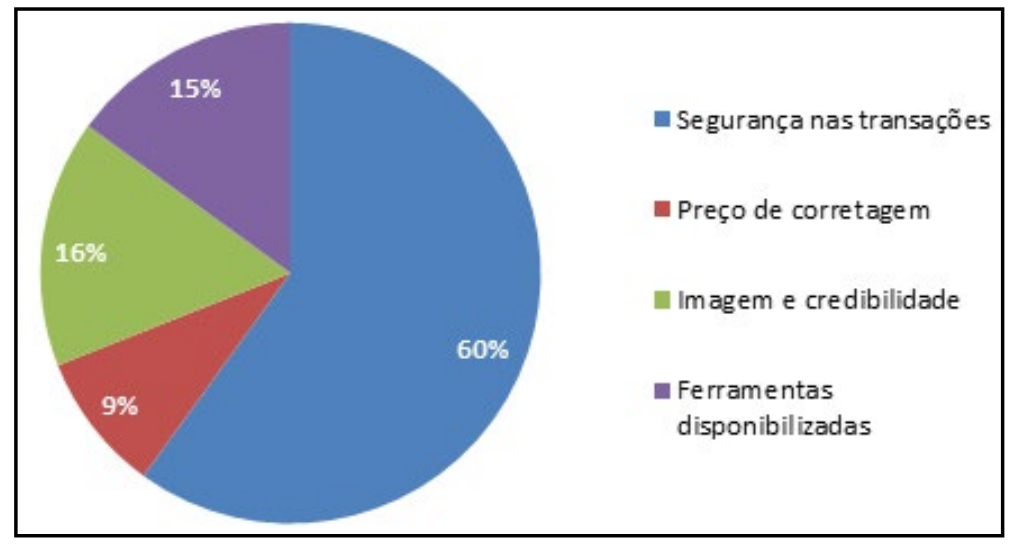

Fonte: Dados da pesquisa (2014)

A fim de comprovar a relação entre as respostas obtidas pelos questionários, realizou-se uma análise de correlação por meio do coeficiente de Pearson, denominado $r$ de Pearson (STEVENSON; GUMPERT, 1985). Os resultados encontrados descrevem a força da relação entre as respostas, sendo uma correlação 0,00 indicadora da ausência de relação entre as variáveis; por outro lado, quanto mais próximo esse coeficiente estiver de 1,00 (com sinal positivo ou negativo), mais forte é a relação.

Os sinais de mais e menos indicam se há uma relação linear positiva ou linear negativa entre as variáveis. É relevante salientar que é a magnitude do coeficiente de correlação que indica a correlação e não o sinal do coeficiente.

Primeiramente, testou-se a correlação entre as variáveis que indicavam a importância de disponibilidade de gráficos, relatórios ou utilização de assessor para auxiliar na tomada de decisão do investidor. Nesse teste, foi possível observar que há um alto coeficiente de correlação entre a disponibilidade de gráficos e de relatórios, sendo este de 0.953316 . Pode-se, então, afirmar a existência de uma correlação forte entre essas duas variáveis, pois se aproximam muito do valor que seria como denominado como uma relação perfeita, que é o de 1,00.

Na relação que diz respeito à disponibilização de relatórios e auxílio de assessor, também se obteve um coeficiente alto - de 0,877012 -, embora seja menor que o primeiro, também demonstra uma relação forte entre as duas variáveis. Já no teste realizado entre as variáveis disponibilidade de gráficos e auxílio de assessor, não se obteve um coeficiente tão alto, foi este de 0,748132; logo, a relação entre essas duas variáveis não é tão forte quanto as outras duas primeiramente examinadas.

Destarte, foi criado um gráfico de dispersão com o intuito de analisar os dados, mostrando, graficamente, a correlação entre eles (Gráfico 7).

Gráfico 7 - Dispersão da correlação das variáveis: gráfico, relatório e assessor

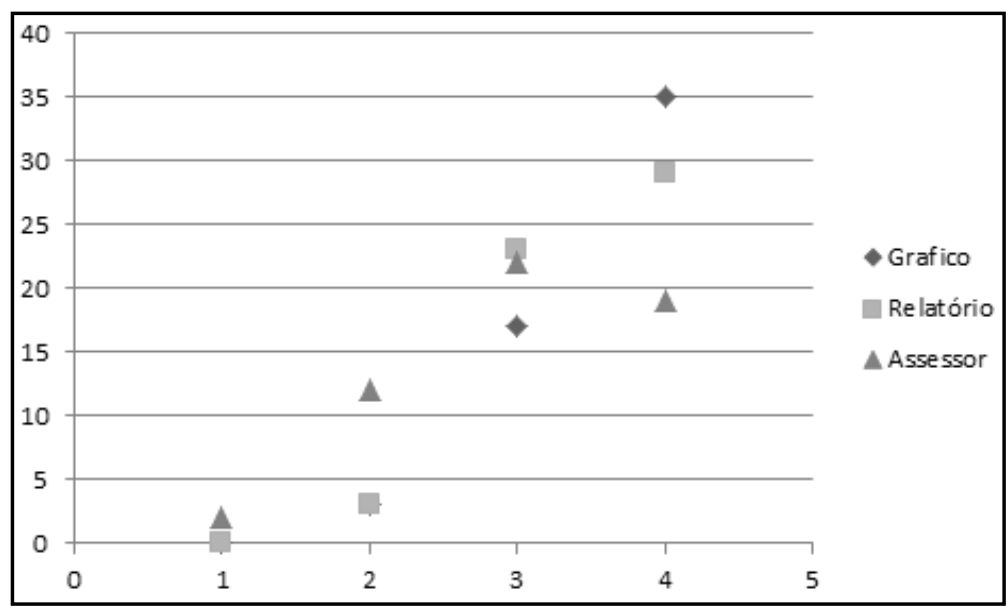

Fonte: Dados da pesquisa (2014)

Por fim, foi realizado o teste de correlação entre as variáveis de influência da política brasileira, do mercado internacional e da cotação do dólar na tomada de decisão dos investidores da amostra. 
Com essa correlação, foi possível verificar que a política brasileira e a cotação do dólar possuem uma relação muito forte entre si, pois o coeficiente foi de 0,977487 , aproximando-se muito do valor de 1,00. Igualmente, a política brasileira e o mercado internacional possuem uma relação forte, em que o coeficiente de correlação é de 0,831102 . Por outro lado, o mercado internacional e a cotação do dólar não possuem uma relação muito forte, o coeficiente de 0,696695 é relativamente baixo comparado aos outros testes realizados.

No Gráfico 8, está demonstrada a dispersão entre os resultados obtidos na pesquisa no que se refere a essas três variáveis testadas.

Gráfico 8 - Dispersão da correlação das variáveis: política brasileira, mercado internacional e dólar

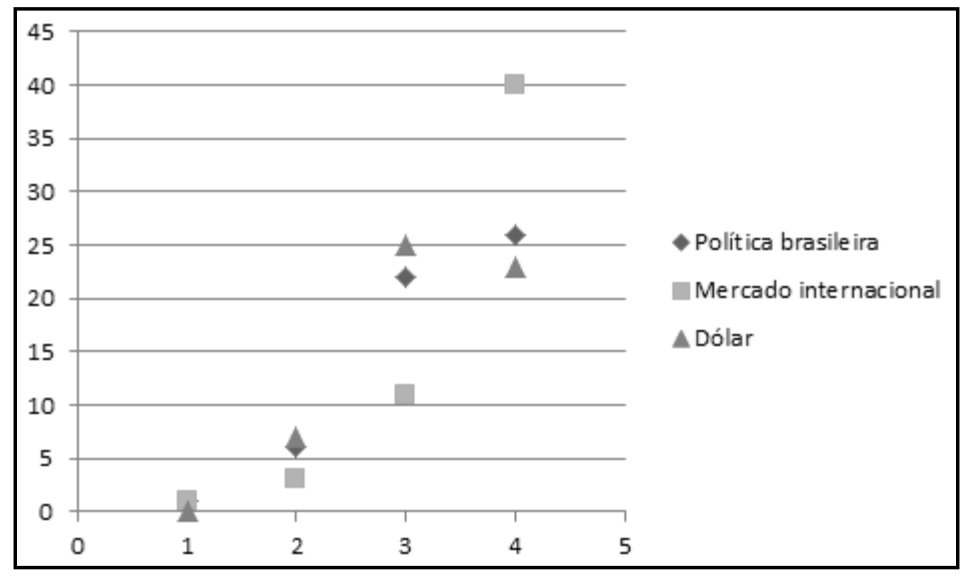

Fonte: Dados da pesquisa (2014)

\subsection{Resultados}

Com base nos dados da amostra, pode-se concluir que os investidores consideram muito importante e um fator prioritário na hora de operar com o home broker a disponibilidade de gráficos para análise de mercado, os quais auxiliam na tomada de decisão. A análise gráfica (Escola Técnica), desse modo, torna-se um fator muito relevante, as corretoras devem desenvolver-se cada vez mais em tal aspecto, a fim de captar mais clientes.

Não obstante, a disponibilidade de relatórios de análise de mercado (Escola Fundamentalista), embora não destacada pelo investidor como fator de pouca importância, revela-se ser menos utilizada e considerada com menos importância que a Escola Gráfica na opinião dos entrevistados. Uma hipótese para tal afirmação poderia ser o fato de não ser tão tangível quanto os gráficos ou sofrerem constantes mudanças em virtude da dinamicidade que o mundo de ações vive.

Ao se questionar qual o instrumento analítico utilizado pela corretora para operar o home broker, buscou-se observar se o investidor tinha algum conhecimento ligado à área de matemática quando efetuava suas transações. Foram estabelecidas cinco alternativas para o investidor, uma referindo-se à Programação Linear, outra à Programação Não Linear e, por último, ao Portfólio Selection, bem como a alternativa de que ele desconhecia o instrumento, ou se havia algum outro não citado anteriormente.

A maioria dos respondentes optou pela alternativa que se referia ao Portfólio Selection, em que a corretora determina todas as carteiras "ótimas", avaliando o risco e retorno de cada uma delas. Dessa forma, é possível fazer uma diluição dos riscos, equilibrando eventuais perdas em alguns investimentos com ganhos em outros. Pode-se observar, então, que o investidor está preocupado em diluir seus riscos, pois não está disposto a arriscar demais, podendo ter como consequência uma perda muito alta.

Observou-se que o Portfólio Selection está diretamente ligado ao Princípio da Diversificação; a maioria dos entrevistados que utiliza mencionado modelo julga ser tal Princípio fator de muita importância. Um entendimento possível seria o de que não adianta diversificar sem nenhum critério, é necessário um processo de avaliação de alocação de capital em diversas oportunidades de ganho (ou perda), por meio da determinação de duas contribuições para a otimização da relação riscoretorno.

Pode-se observar que o investidor atual não está disposto a correr muitos riscos, buscando ao máximo equilibrar a relação risco-retorno. Igualmente, ele se baseia na hora da tomada de decisão em análises gráficas, procurando realizar simulações para avaliar seus riscos e suas possibilidades de 
ganho.

Outro aspecto pesquisado diz respeito aos fatores macroeconômicos que mais influenciam no momento da tomada de decisão do investidor, assim como as consequências mais importantes ocasionadas por mudanças nesses fatores. Os fatores que foram disponibilizados no questionário são os que sofrem constantes mudanças no dia a dia. Estes foram: relatórios de análise de mercado, cotação do dólar, índice Bovespa, política brasileira e política internacional.

Dentre esses fatores o que os entrevistados marcaram com maior frequência possuir uma alta influência em suas carteiras de ações foi a política internacional, pois acreditam que ela influencia diretamente no preço das ações que eles possuem. Como o mundo encontra-se em uma fase globalizada, essa opinião é completamente compreensível, pois os valores das ações variam de acordo com as reações e políticas internacionais.

A política brasileira, na opinião dos mesmos entrevistados, também possui uma influência relevante, mas não tanto quanto as internacionais. Mostrando, assim, certa descrença, por parte dos investidores, em relação à influência da política brasileira no mercado das ações.

Por outro lado, constatou-se que o dólar já não possui tanta influência no preço das ações. Devese isso a uma estabilização do dólar, fazendo com que, dessa maneira, não cause tanta insegurança aos investidores, pois não possui mais a influência que possuía antigamente. O índice Bovespa é outro fator que influencia muito para o investidor, mas ele acredita que, mesmo com as oscilações do referido índice, não significa que acarretará uma perda ou ganho por consequência dessas mudanças constantes.

Outro aspecto que pôde ser observado por meio do questionário foi o que remete ao que o investidor credita ser mais relevante no momento de escolher a corretora pela qual ele operará a ferramenta home broker.

Preliminarmente, foi constatado que, entre as opções segurança das transações, preço da corretagem, imagem e credibilidade do portal, e ferramentas disponibilizadas pela corretora, a opção considerada pelos entrevistados como a mais importante é a segurança nas transações. Isso mostra que, com o aumento da tecnologia, há uma probabilidade maior que mais pessoas de má-fé detentoras desse conhecimento da tecnologia podem usá-la para fraudar transações, prejudicando, assim, o investidor. Por esse motivo, o investidor leva muito em conta o aspecto da segurança de suas transações.

Com o desenvolvimento da Tecnologia da Informação, o investidor torna-se cada vez mais exigente no que concerne às ferramentas disponibilizadas pela corretora para auxiliá-lo na sua tomada de decisão. Ele julga muito importante a disponibilidade de gráficos para auxiliá-lo, assim como de relatórios de análise de mercado. Assim sendo, os entrevistados acreditam ser importante um serviço de monitoramento dos preços dos papéis com aviso sobre os preços de ativos, de ações e estratégias de investimentos.

Acerca da importância de um assessor, constatou-se que nem todos os entrevistados julgam ser muito importante, em razão do alto custo desse serviço, bem como pelo fato de desconfiarem do serviço de tais profissionais, por terem alto conhecimento a respeito do mercado de ações, e o pagamento desses operadores ser feito por meio de comissões sobre as transações. Logo, depois que o investidor possui um maior conhecimento sobre o mercado acionário e possui tempo de acompanhá-lo, ele acredita que o auxílio de um assessor pode ser dispensável.

O último ponto analisado foi o fator preço de corretagem, que, embora não esteja no topo das prioridades dos investidores, é sempre algo relevante quando da escolha da corretora. Muitas vezes, dependendo da quantia a ser investida e do valor de corretagem, não é vantajoso para o investidor aplicar seu dinheiro no mercado de ações, mas sim em outro investimento. A maioria das pessoas considera o preço da corretagem na escolha sua corretora.

\section{CONSIDERAÇÕES FINAIS}

O presente estudo foi realizado com o intuito de analisar a importância da utilização de modelos matemáticos e suas ferramentas (gráficos e relatórios) no processo de investimento home broker na concepção do investidor. Também buscou identificar os fatores que influenciam o investidor na escolha de uma corretora para realizar suas operações home broker e os aspectos macroeconômicos que implicam sua decisão de investimento.

Por intermédio do questionário, foi possível coletar, dentro da amostra de pesquisa, respostas acerca do comportamento do investidor que utiliza a ferramenta home broker no que tange à utilização 
de modelos matemáticos. Além disso, foram obtidas respostas acerca dos efeitos ocasionados pelas variáveis econômicas, na concepção dos entrevistados, em suas decisões de investimento. Uma terceira parte do questionário permitiu coletar informações sobre quais fatores, na perspectiva dos respondentes, poderiam ser entendidos como mais relevantes para o investidor no momento da escolha da corretora para operar a ferramenta home broker.

Com os resultados obtidos, foram realizadas estatísticas básicas de todas as respostas e algumas correlações entre grupos de respostas. Tais análises buscaram identificar o comportamento do investidor que utiliza o sistema home broker quanto à aplicação de modelos matemáticos e suas ferramentas (questões 5, 6, 10 e 11), quanto ao uso de relatórios de análise de mercado, cotação do dólar, índice Bovespa, política brasileira e política internacional (questões 12, 13 e 14) e quanto aos fatores que influenciam esses investidores na escolha da corretora de ações (questões 3, 4, 8, 9 e 16).

Concluiu-se que os investidores da amostra da pesquisa, em sua maioria, fazem uso superficial de gráficos e relatórios oriundos de modelos matemáticos. Tal superficialidade deve-se ao fato de eles não possuírem conhecimento acerca do arcabouço teórico-matemático que fundamenta tais ferramentas. Isso fica evidente na questão a propósito do princípio da diversificação. Os respondentes não estabeleceram relação entre esse princípio e o uso do Portfólio Selection ou de cadeias de Markowitz.

Verificou-se, ainda, na amostra da pesquisa, que a escolha da corretora de ações se dá em virtude da segurança na realização da transação, em detrimento de outras opções, tais como o preço de corretagem, as ferramentas de simulação oferecidas e a funcionalidade do portal da corretora.

Complementarmente, foi possível identificar que os respondentes consideram a política internacional como o fator macroeconômico mais importante na análise de uma carteira de investimentos. A política interna brasileira ficou posicionada em um nível intermediário de importância. O dólar, segundo a concepção dos investidores da amostra, foi considerado como de importância relativa e dependente da política internacional e nacional.

Como contribuições do presente trabalho, ressaltam-se a análise do comportamento do pequeno investidor em bolsa de valores e a identificação das formas como ele analisa as oportunidades de investimento.

Como principal limitação da pesquisa, têm-se as particularidades as quais se reveste um estudo do tipo exploratório. Os resultados obtidos não podem ser generalizados para outras situações sem que seja levado em conta o tamanho da amostra e a forma de escolha dos respondentes.

Com base nessa limitação, surgem as recomendações para futuros trabalhos. Sugerem-se novas pesquisas que tratem do tema do pequeno investidor e da ferramenta home broker sob a perspectiva das corretoras que oferecem tal modalidade. Outra possibilidade é a análise dos resultados financeiros obtidos por meio do investimento feito via home broker em comparação ao realizado via operação normal de bolsa de valores.

\title{
A STUDY ON THE IMPORTANCE ASSIGNED BY INVESTORS TO THE USE OF MATHEMATICAL MODELS IN HOME BROKER PRACTICES
}

\begin{abstract}
This paper proposes the examination of the degree of importance assigned by small investors involved in home broker modality in what concerns the use of mathematical models in the process of choosing their investments. The research is characterized as an exploratory study with literature and field review. Data was collected through the use of questionnaires, which was then submitted to descriptive, statistical and inferential analysis. Based on the analysis of the sample, the study comments on the use of charts and reports derived from mathematical models, regarding the investor's criteria for selecting the brokerage to the detriment of the functionality and simulation tools offered by the electronic portal. In addition, it identifies the importance given by respondents to international political factors, Brazilian domestic politics, and the quote of international currency.
\end{abstract}

Keywords: Investment decisions. Home broker. Mathematical models. 


\section{REFERÊNCIAS}

ANDERSEN, C. E. Home broker: Como Investir em Ações pela Internet. São Paulo: Ciência Moderna, 2006.

ASSAF NETO, A. Mercado Financeiro. São Paulo: Atlas, 2003.

BRATTI, D. Sistema informatizado para auxiliar o pequeno investidor na bolsa de valores. 2009. 398 p. TCC (Graduação em Ciências da Computação) - Universidade Federal de Santa Catarina, Florianópolis, 2009.

COLIN, E. C. Pesquisa Operacional: 170 aplicações em estratégias, finanças, logística, produção, marketing e vendas. Rio de Janeiro: LTC, 2007.

CORRÊA, A. C.; SOUZA, A. B. 2001. Fronteira eficiente de Markowitz: aplicação com ativos brasileiros. Adcontar, Belém, v. 2, n. 1, p. 7-10, maio 2001.

FORTUNA, E. Mercado Financeiro: produtos e serviços. Rio de Janeiro: Qualitymark, 2005.

LONGARAY, A. A. Introdução à Pesquisa Operacional. São Paulo: Atlas, 2013.

LOPES, A. L. M. et al. Utilizando data envelopment analysis-dea e o modelo de otimização de Markowitz na seleção de ativos no mercado de renda variável brasileiro. In: SIMPÓSIO BRASILEIRO DE PESQUISA OPERACIONAL, 41., 2009, Porto Seguro. Anais... Porto Seguro: UNIFACS, 2009. p. 1-12.

KAWAMOTO, C. Projeção da Penetração do Home broker no Mercado de Capitais Brasileiro através dos Modelos Linear, Fisher-Pry e Gompertz. Future Studies Research Journal, São Paulo, v. 2, n. 1, p. 33-51, 2010.

MARKOWITZ, H. Portfolio Selection. The Journal of Finance, American Finance Association, v. 7, n. 7, p. 77-91, 1952. Disponível em: < https://www.math.ust.hk/ maykwok/courses/ma362/07F/ markowitz_JF.pdf >. Acesso em: 18 dez. 2014.

GONCALVES Jr., C; PAMPLONA, E. O.; MONTEVECHI, J. A. B. Seleção de carteiras utilizando o modelo de Markowitz para pequenos investidores. In: SIMPÓSIO DE ENGENHARIA DE PRODUÇÃO - SIMPEP, 9., 2002, Bauru. Anais... Bauru: UNESP, 2002. p.1-10.

MOTTA JUNIOR, N; OLIVEIRA, U. R.; GUTIERREZ, R. Minimização de riscos de Investimentos em Carteiras de Ações através da Pesquisa Operacional. In: SIMPÓSIO DE EXCELÊNCIA EM GESTÃO E TECNOLOGIA - SEGET, 4., 2007 Resende, 2007. Anais... Resende: EADB, 2007. p.1-15.

PINHEIRO, J. L. Mercado de Capitais: fundamentos e técnicas. São Paulo: Atlas, 2009.

ROESCH, S. M. Projeto de estágio e de pesquisa em administração. São Paulo: Atlas, 2005.

STEVENSON, H. H.; GUMPERT, D. E. The Heart of Entrepreneurship. Harvard Business Review, Boson, MA, v. 63, n. 2, Mar./Apr. 1985.

TESTA, C. H. R. Aplicação da estratégia de investimento de Graham à bm\&fbovespa para o pequeno investidor. In: SemeAD-Seminários em Administração, 14., 2011, São Paulo. Anais... São Paulo: USP, 2011. p.1-12.

VASARHELYI, M. A. Aplicação de modelos em administração financeira. Revista de Administração de Empresas, São Paulo, v. 16, n. 3, p. 7-13, 1976. 